\title{
Manuel Pereira ou a poética da precisión
}

\author{
BEgoña REgueIRo SALGADO \\ Universidad Complutense de Madrid \\ bregueirosalgado@edu.ucm.es
}

Recibido: junio 2012. Aceptado: julio 2012

\begin{abstract}
Resumo: O seguinte artigo revisa a adscrición de Manuel Pereira Valcárcel a un grupo poético e fai un percorrido pola obra do autor publicada entre 2005 e 2012. A partir desta análise, establécense as liñas principais da escrita de Manuel Pereira, tanto na poesía como na prosa, e conclúese a pertenza do escritor ao Grupo Poético Bilbao, de poetas de expresión galega que viven en Madrid.
\end{abstract}

Palabras chave: Manuel Pereira Valcárcel, Grupo Poético Bilbao, poesía galega do século XX, poesía da precisión.

Resumen: El siguiente artículo revisa la adscripción de Manuel Pereira Valcárcel a un grupo poético y hace un recorrido por la obra del autor publicada entre 2005 y 2012. A partir de este análisis, se establecen las líneas principales de la escritura de Manuel Pereira, tanto en la poesía como en la prosa, y se concluye la pertenencia del escritor al Grupo Poético Bilbao, de poetas de expresión gallega que viven en Madrid.

Palabras clave: Manuel Pereira Valcárcel, Grupo Poético Bilbao, poesía gallega del siglo XX, poesía de la precisión.

« ¡Como pasa o tempo, meu Deus! - Si, el corre decote, non se está quieto, aínda que as veces pareza que non da pasado» (Malas cartas: 2010: 57).

E mesmo na vida que na literatura que trata de reflectila, o tempo non para. Así, hai xa sete anos que coñecín a Manuel Pereira e tiven a sorte de mergullarme nos seus versos. Sete anos hai que se publicou o artigo no que trataba de atoparlle o grupo, a clasificación perfecta, e no que facía o estudo dos seus primeiros libros de poemas: Poemas de cinza (Edición de autor, 1990), Todo Morte (Río Xuvia 1998), Rosa íntima (Espiral Maior 2000), Inventario de fragmentos (Follas Novas 2001) e Libro das viaxes (Hipocampo 
Amigo de Poesía, 2002) ${ }^{1}$. Moito choveu dende entón e, entre outras cousas, a choiva trouxo máis poemas e máis libros, mesmo de relatos que novelas.

Á vista destas últimas publicacións, o que vou tratar de facer neste traballo é unha actualización dos estudos verbo Manuel Pereira, así como unha revisión da clasificación que fixera entón.

\section{UNHA VOLTA DE TORCA: NOVAS PERSPECTIVAS SOBRE A CLA- SIFICACIÓN DE MANUEL PEREIRA}

Manuel Pereira Valcárcel nace en Ouzande (A Estrada) no ano 1955, e publica o primeiro libro de poemas en 1990. Deste xeito, de acordo coas clasificacións tradicionais, pola data de nacemento habíamos de situalo xunta dos poetas dos oitenta, como Francisco Salinas e Xosé Miranda, que nacen no 1950; Cesáreo Sánchez (1951), Mato Fondo, Xulio Valcárcel e Claudio Rodríguez Fer (1953), Xavier Seoane (1954); Pilar Pallarés e Manuel Rivas, que nacen en 1957; Fernán-Vello, Lois Pereiro e Manuel Forcadela, do 1958. Por outra banda, pola data de publicación, aliñaríase cos poetas dos 90, como Martín Veiga Alonso ou Miro Villar. Con todos eles, comparte algúns trazos. Así, segundo a caracterización que Basilio Losada fai dos poetas dos oitenta, Manuel Pereira compartiría con estes autores algo do culturalismo, a preocupación polos aspectos formais, a palabra vivencial, a comunicabilidade e algúns temas, como o amor e a sensualidade, o tempo, a morte, a presenza da natureza, o carácter elexíaco, a epicidade, o civismo, e a reflexión sobre a escritura e a metapoesía. Cos poetas dos noventa, pola súa parte, compartiría a fuxida do venecianismo, a tendencia ao discurso intimista, o gusto polos espazos interiores e cotiáns, a aposta polo verso libre e os ecos de voces interiores (características apuntadas por María Xesús Nogueira).

Con todo, se miramos nas antoloxías que se fixeron destes autores, atopamos que ningunha delas recolle a obra de Manuel Pereira. Que pasa entón? Cando fixen o artigo que mencionei máis arriba, pensaba que a resposta era un deficiente estudo do autor. Hoxe, manteño a idea de que a poética e a narrativa de Pereira merecen un estudo máis profundo e detido, pero xa non estou tan certa que a súa ausencia nas citadas antoloxías responda a iso. O mesmo Valcárcel afirmaba, nunha entrevista feita no 2005, que non consideraba que existise un cambio real e radical nas poéticas dos oitenta e dos noventa e, engadiría eu, tampouco unha fenda demasiado grande entre estas e as que viñeron despois, a pesar de que Vicente Araguas afirme que: «Los poetas del 2000 se vienen caracterizando por una ruptura brusca con la generación anterior» (cit en Mejía, 2003:211). A razón pola cal non se percibe esta fisura é que o poeta evoluciona cos tempos e, se como dixemos, na obra de Valcárcel podemos atopar concomitancias cos poetas dos oitenta, tamén as atopamos cos dos noventa e cos de 2000, porque a súa obra segue viva. Así, dende o meu punto de vista, poderia-

1 Regueiro Salgado, Begoña (2006) «Manuel Pereira Valcárcel: poesía de la experiencia en la Galicia actual», Madrygal, 9: 103-113. 
mos tratar de clasificar as obras segundo estean máis preto dunha tendencia ou de outra, podemos falar de datas de nacemento ou primeiras publicacións, pero, dende a contemporaneidade e a falta de tantas outras datas e contactos literarios que poden determinar ou dar un xiro á súa obra, non nos é posible acertar o posto que a Historia da Literatura lle dará. Si podemos, porén, facer unha clasificación máis sincrónica, tomando como punto de referencia o espazo. É o que fai, por exemplo, Luciano Rodríguez na antoloxía Desde a palabra, doce voces. Nova poesía galega. Neste caso, o antólogo fala de tres núcleos de poesía galega: Vigo, Coruña e Santiago. O criterio é bó, pero a clasificación insuficiente. Como demostrou Ana Acuña na súa tese de doutoramento, Facer literatura galega en Madrid (1950-2000), hoxe non é posible estudar a literatura galega sen termos en conta o que se fai en Madrid. E Manuel Pereira Valcárcel é un dos poetas máis representativos da literatura galega en Madrid.

Podemos dicir que, dende o ano 96, falar de literatura ou poesía galega en Madrid, pasa por falar do Grupo Bilbao. O Grupo Bilbao xorde neste ano, na presentación do libro $O$ gato branco, de Vicente Araguas, como idea de Xavier Frías. Dende entón, este grupo heteroxéneo, que recibe o nome a partir do faladoiro celebrado no café Comercial (na glorieta de Bilbao) o último sábado de cada mes, vén sendo un dos motores da cultura galega en Madrid. Nestas xuntanzas mensuais participan poetas, pero tamén profesores de galego de diversas universidades e institucións, e todo aquel que queira rodearse de cultura galega por un par de horas. Deste xeito, alí, nas mesas de mármore branco, arrodeadas de espellos, naceron iniciativas como a colección de cadernos poéticos $O$ Roibén, que apareceu en 1998; a editorial Alcálima, do 2004; ou as publicacións colectivas Comercial (1998), Muller de doce sal. Homenaxe a Inés Canosa (2000) ou En tránsito (2001), antoloxía coordinada por Manuel Pereira e Vicente Araguas que recolle a obra de poetas en lingua galega que, ao longo da historia, viviron e escribiron en Madrid. Durante algúns anos, a actividade do grupo descendeu até quedar, case, reducida a reunión mensual e aos encontros en actividades como as Estacións Poéticas, organizadas por Vicente Araguas na Casa de Galicia até que Alfonso Palomares foi destituído no seu cargo de director da Casa, en abril de 2009. Porén, dende hai tres anos, grazas, de novo, á iniciativa editorial de Frías, as antoloxías e os recitais colectivos do grupo volveron facerse regulares. Deste xeito, en 2010, foi publicado Marés nos pousos de café. Mostra de poetas de expresión galega en Madrid, coa participación de Vicente Araguas, Xosé Miguel Barrera, Ana Cibeira, Xurxo Fernández, Xavier Frías, Luis Luna, Manuel Pereira, Begoña Regueiro e Rafael Yáñez, e, en 2011, se publicou o libro de microrrelatos E Madrid foi unha praia de baleas entre néboas, con textos de Vicente Araguas, Ana Cibeira, Xavier Frías, José Galán, Pili Meras, Jurjo Novóa, Manuel Pereira, Begoña Regueiro e Marga Vázquez. Ambos libros foron presentados con sendos recitais no centro asociado á UNED das Escolas Pías e, amais destes, se fixeron outras lecturas colectivas no marco da presentación do Instituto Cultural Brasil-Galiza (celebrado na casa de Brasil, o 23 de outubro de 2010, baixo a organización de Xurxo F. Martíns) o da II Semana Complutense das Letras (abril de 2012), neste caso, grazas o labor de Carmen Mejía e Ricardo Pichel. Igualmente, e, nestes casos, cunha importante participación de Manuel 
Pereira, fixéronse homenaxes como o «Saúdo Poético a Mariví Villaverde» o 23 de marzo de 2010.

Como se pode ver, hai moitos nomes asociados a este grupo, xente máis o menos nova que vai chegando ou xente que marcha, pero a que está clara é a presenza constante de tres figuras: Vicente Araguas, Xavier Frías e Manuel Pereira Valcárcel. Podería dicirse que son estes a ánima do grupo, os poetas consagrados, os «pais», como mostran tamén iniciativas como o recital do vinte de xaneiro de 2011: «Dous poetas galegos en Madrid: Vicente Araguas e Manuel Pereira».

Chegamos, así, ao punto inicial, é dicir, a clasificación de Manuel Pereira Valcárcel. Se, como se dixo, a clasificación no tempo precisa do mesmo tempo para afianzarse, si que podemos buscar outros xeitos de relación e podemos afirmar, sen medo ao erro, que Manuel Pereira ten que ser asociado ao grupo de poetas galegos de Madrid, o grupo Bilbao, no que, ademais, desenrola un papel fundamental como guía e promotor de actividades.

\section{A OBRA DE MANUEL PEREIRA ENTRE 2005 E 2012: TRAXECTOS CURTOS, DÍAS DO FINAL, MALAS CARTAS E TATUAXES.}

Do mesmo xeito que a actividade de Manuel Pereira foi intensa nos últimos anos no que se refire á participación en actos, foino tamén nas publicacións e, así, entre 2005 e 2012, atopamos catro libros novos e a reedición de Todo morte, en Ediciós do Castro, en 2006.

Se nos fixamos nos títulos novos, o primeiro que chama a atención é que, esta vez, non se trata de libros de poemas, senón que atopamos libros pertencentes a distintos xéneros. Así, Traxectos curtos é unha colección de relatos, mentres que Días do final e Malas Cartas son novelas e só Tatuaxes é poesía. Sempre é unha incógnita como imos atopar o poeta transmutado en novelista e viceversa. Porén, neste caso, como pretendo probar, non existe tal cambio e segue a ser o poeta ourive da precisión e a palabra o que se deixa ver tras a prosa.

Se comezamos coa análise de Traxectos curtos, habemos dicir que aparece en 2005 na editorial tresCtres. O libro consta de doce relatos, todos eles precedidos por un poema, (que, inda que adoita tratar o tema das viaxes, idas ou retornos, non sempre ten relación directa co relato ao que precede), e nove fotografías, nas que queda patente unha nova tendencia que o autor vai repetir en Tatuaxes e que deixa ver o seu gusto pola imaxe.

Como o título apunta, o fío condutor do libro ou o tema que reúne todos os contos e a viaxe, pero non a viaxe xeral, senón a viaxe curta, a transición, a estación de paso, como se refire a elas o autor en máis dunha ocasión. Estes tránsitos ou traxectos curtos son polisémicos porque, se ben, nalgúns casos corresponden, de feito, a desprazamentos de pouca duración, noutros, a dimensión espacial desaparece e o traxecto fai referencia ao intre compartido, ao cruce de camiños momentáneo, mesmo, ao instante que se sae das rutinas no medio da vida cotián e fai que todo teña senso de novo, a pesar das repeticións. «As cou- 
sas que se repiten tanto rematan por non existir» (68), di o autor no relato «Proximidade».

No primeiro dos casos, atopamos percorridos feitos en todo tipo de transporte: o autobús, en De paso; o coche, en Días de praia; o tren en Ao outro lado e Unha semana despois; o metro, en Subterráneos, e, mesmo, as propias pernas en Puntos cardinais, no que a voz narrativa compara o seu calmoso xeito de desprazarse a pé cun avión que pasa por riba del mentres está deitado descansado. A vertixe, a asombrosa velocidade fronte a lentitude que permite apreciar cada pequeno cambio no camiño.

Como dicía, noutros relatos o traxecto curto e o tempo breve compartido cunha persoa coa que intercambiar puntos de vista, cunha persoa que percorre con nós só unha mínima parte do camiño, pero que pode facernos reflexionar ou descubrir algo. Así ocorre en Diapositivas e Ida e volta, nos que se presentan encontros momentáneos, de amigos en torno as fotografías do verán, no primeiro, e de compañeiros de traballo cunha relación que non vai máis alá do tempo de oficina, no segundo.

Por último, quedaría mencionar unha terceira tipoloxía de desprazamento: o que se fai de xeito suxerido, é dicir, o que se produce grazas ás fotografías ou grazas ás sensacións transmitidas pola arte, como sucede no relato Subterráneos, no que a música leva a outro tempo e outro espazo durante os minutos que dura a canción, outro traxecto curto.

En calquera dos casos, a importancia do momento radica no intercambio, no encontro no medio da viaxe, da contraposición de puntos de vista que pode levar a afondar nun tema, a confrontalo ou, simplemente, a constatar como funcionan os prexuízos verbo dalgunhas materias.

Neste caso, os temas que aparecen de xeito recorrente nos relatos son: a metaliteratura (De paso, Mentres conduzo), o paso do tempo (De paso), as relacións que se establecen entre xeracións (Días de praia, Ida e volta, Errare humanum est), os erros aos que conducen os prexuízos ou as primeiras impresións (Unha semana despois, Errare humanum est) e o tema que, en realidade, acolle a todos os demais: as formas de viaxar ou, o que é o mesmo neste caso, as formas de vivir e de afrontar a vida: ás presas ou á modo (Puntos cardinais), fuxindo á carreira do paso do tempo ou buscando a estabilidade do espazo onde o tempo non deixa de voltear as cousas (De paso), sendo capaces de mirar a vida doutro xeito despois de crebar a rutina ou non (Proximidade), etc.

Como dicía, en calquera dos casos, o importante é a fugacidade do intre compartido que pode non volver repetirse nunca mais. Quizais é a importancia desta fugacidade a que fai que en case todos os relatos aparezan as estacións do ano no que ocorren, como outras estacións de paso que fannos decatar do correr do tempo.

En canto a técnica, o libro destaca pola variedade. Así, atopamos relatos escritos en terceira persoa (De paso, Ida e volta, Proximidade), e relatos en primeira persoa con narradores de distintas idades e situacións (Día de praia, coa voz narrativa dun adolescente de quince anos; Mentres conduzo, no que o na- 
rrador é un adulto que vai facendo microcontos a partir do que observa mentres conduce; Errare humanum est, no que a narración en primeira persoa se divide entre dúas voces que, cun monólogo interior, van amosando os seus prexuízos acerca do outro e, despois, o erro que cometeran con eles; e Diapositivas).

En todos eles, é interesante subliñar o particular xeito de introducir os diálogos, pois non se fai de forma tradicional con guións, senón que, ou ben se marcan as distintas intervencións coa tipografía sen sacar o texto do parágrafo, ou ben, sen sequera esa axuda, como se se tratase de estilo indirecto libre, se introducen as intervencións dos personaxes sen previo aviso.

Outro elemento que convén destacar en relación ao estilo, sobre todo pola recorrencia do recurso, é o uso dunha prosa lírica que se apoia na maior parte dos casos nos paralelismos. Podemos atopalo, por exemplo, no relato Ao outro lado, no que todo o relato se constrúe sobre os pensamentos paralelos dos dous personaxes que, porén, non chegan a establecer unha conversa. Do mesmo xeito, con frecuencia, o autor emprega as enumeracións de substantivos para presentar realidades ou imaxes con este estilo nominal e faino mesmo na prosa que nos poemas. Vémolo, por exemplo, no seguinte fragmento:

Día a día. Idas e vidas. Semanas tras semanas. Meses ensartados. Anos en sucesión. Son coma soños, emociónanme, divírtenme, sorpréndenme, acompáñanme. Distráenme máis ca ningunha música, mellor que calquera emisora de radio. Rematan coa chegada, co termo. Relatos fráxiles, esvaedizos e combustibles (2005: 53).

Para rematar, tamén operando na construción do lirismo e revelando o poeta, con frecuencia, atopamos frases, sentenzas que mesmo parecen versos. Verémolo tamén nos outros libros en prosa. Neste caso, podemos lelo, por exemplo, no seguinte texto: «Cando se cre ter a felicidade, é imprescindible saber as súas fronteiras para non forzar os seus límites» (130).

O seguinte libro que sae publicado nestes anos (sen termos en conta a reedición de Todo morte) é Días do final, que aparece en 2007 na editorial Galaxia.

Esta vez, o que sostemos nas nosas mans é unha novela, pero non é unha novela tradicional, senón a novela dun poeta, como amosan a extensión, o lirismo, a precisión da linguaxe e, mesmo, o carácter biográfico que a dota de parte da subxectividade da poesía.

Días do final é, pois, unha novela de cincuenta e sete páxinas, dividida en cinco secuencias separadas por espazos en branco pero sen título nin numeración. Como xa dixen, trátase dunha obra autobiográfica na que o narrador relata os derradeiros días da vida do seu pai. O tema, por tanto, volve a ser a morte rodeada das consideracións que esta obriga a facer respecto da vida. 
Os mortos non regresan a nós para recordarnos a súa existencia, para afianzar unha fidelidade indecisa. Somos nós os que regresamos a eles, un latexo de memoria, unha paisaxe de evocación que nos require.

Non precisan nada os defuntos, pero se queremos estar seguros da lembranza, de vez en cando cómpre o agasallo das flores ou algún tipo de oración. Son pequenos detalles que nos fan sentir vivos, porque valoramos todo en oposición ao contrario, tamén a vida. Esta soa moeda que á fin nos será arrebatada e que eles, os definitivamente ausentes, xa perderon (2007:9).

Esta é a reflexión que abre o libro, que parece presentarse así como esa flor ou oración que a lembranza procura. Despois da reflexión, dous parágrafos introdutorios serven para situar ao lector case dez anos despois dos feitos e para que a visión do Hospital Xeral sirva como escusa para o recordo, como o que fai que se activen «todas as ferramentas que usan as lembranzas para evidenciarse» (11).

Dá comezo así a narración dos días do final, dende o momento en que unha chamada telefónica avisa do ingreso en urxencias do pai e motiva a viaxe, até a morte, a finais de agosto. Trátase case dunha elexía escrita ao revés, na que non hai espazo para o lamento e na que, despois da morte, queda só o silencio.

Deste xeito, a novela dá comezo uns meses antes dese final de agosto no que ocorre o pasamento, nunha primavera na que o bulir da vida contrasta coas eternas horas de hospital, como o mesmo Pereira fai notar nun poema de Todo morte (libro cunha conexión clara con este), no que resume en sete versos o que desenvolve en Días do final.

Días e noites xiran en órbitas de anestesias e transfusións

Fóra do hospital os repetidos rituais da primavera

A desexada volta á casa

Tenrura e cereixas

A morte escolleu un mencer de agosto

Camelias e o agarimo do lume cando o inverno doe

A túa lembranza pai.

(2006:44)

Tres das cinco secuencias transcorren no hospital, e as dúas últimas, xa de volta, na casa, cando a fin é irremediable, pero o corpo permite estar fóra dos muros hospitalarios. Así, como parece lóxico, sen termos en conta os personaxes principais (o pai e o irmán do narrador), a maior parte dos personaxes que aparecen, agás a muller e a filla, están relacionados co espazo do hospital e son doutores ou outros pacientes. Coñecemos así á doutora Rabuñal, gabeada pola súa dozura e optimismo, á enfermeira Rosa e aos compañeiros de cuarto: Primitivo e a súa familia (o fillo, Herminio, e a nora, Dorinda), Sonia (que, neste caso encarna o pesimismo fronte ao paso do tempo e a vellez) e o seu pai, e Suso.

De tods xeitos, nunha novela que se podería caracterizar pola emotividade e a lacrimosidade, o que máis destaca é a contención, a narración nun ton case aséptico e racional que non se deixa levar pola emotividade. Isto, que podería pa- 
recer natural, responde, porén, a unha serie de recursos que o autor emprega. Dous deles son, probablemente, os máis relevantes para conseguilo. O primeiro sería a construción dun ritmo tensión-distensión constante que non deixa espazo para as bágoas. O segundo, un coidado minucioso da parte formal que limita a tensión. Deste segundo trazo, podemos atopar exemplos en calquera das páxinas do libro. Do primeiro, inda que con máis sutileza, tamén. En realidade, poucas veces chegamos ao límite da emotividade, porque o autor emprega outros recursos, que agora analizaremos, para evitalo. Inda así, hai partes da obra nas que parece que un nu empeza a facerse na gorxa, pero, antes de que poda facerse de todo, o autor corta o parágrafo e, no seguinte, volve a un dos temas que cobren a dor. Así, por exemplo, ocorre na páxina 25 ou na 52. No primeiro dos casos, a endereza, a esperanza do pai tras unha punción lumbar, nun intre no que o lector xa sabe que a esperanza é falsa, leva ao límite, pero tras dicir:

Estaba convencido de que despois daquelas incomodidades viría o tratamento e a curación. Ese ánimo nel era o meu acougo.

Muda completamente o tema:

Dende a ventá do cuarto víase a rúa. En fronte novos edificios de oficinas... (25).

O mesmo ocorre no segundo exemplo. Neste caso, o fragmento máis emotivo fala da tristura do pai: «víao chorar cun pranto fondo e calado» (52) e, a continuación: «Había que construír outro treito de rutinas e normalidade» (52). Con esta frase o autor revela unha das técnicas empregadas durante toda a novela. Un dos velos cos que se cobre a tristura é a rutina. Por iso, vai crear novas rutinas agora e, por iso, antes describiu con minuciosidade as rutinas hospitalarias.

A análise das sensacións, a súa racionalización é outro dos mecanismos que o autor emprega para manter a neutralidade. El mesmo explícao así cando di:

Nos momentos de adversidade emocional conflúen en min dous sentimentos con aparencia contraditoria. Por unha parte, unha irreprimible necesidade de chorar e, en oposición, unha frialdade absoluta para analizar a situación (20).

Outro recurso que suaviza a dor é a beleza que se fai presente por medio de versos de distintos poetas (Emily Dickinson Miguel Hernández, Nicanor Parra, Valle Inclán, León Felipe, Vicente Aleixandre, Álvaro Cunqueiro e os cataláns Miquel Martí i Pol e Joan Vinyoli), pero, tamén, por medio das conversas verbo literatura ou cine que se mantén coas outras persoas do hospital. Ademais diso, as reflexión xerais ou abstractas sobre a sociedade, o estado da sanidade pública, as figuras culturais, políticas ou deportivas do momento, ou, mesmo, as reflexións abstractas sobre a vida ou a morte, apartan a mente e ao lector da dor concreta da morte con nome propio.

Todo isto faino o autor para manter a contención da que falabamos ao principio, pero tamén serve para darlle un toque de maior realismo ao libro. En primeiro lugar, a tensión constante no é posible no ser humano, polo que a presen- 
za das charlas irrelevantes no hospital ou á mención aos pequenos detalles dos rituais hospitalarios dan un toque de realidade á obra e fan a situación recoñecible para calquera que teña estado no hospital. Por outra banda, as digresións sobre acontecementos do momento (maio, xuño, xullo, de 2004) adscriben os feitos a un momento moi concreto na historia e axudan ao lector a saber non só de que ano falamos (que, en calquera caso, quedaría claro) senón, tamén, que estaba a pasar entón. Así, por exemplo, lemos:

Naquel 94 Galicia vivía pendente de tres acontecementos deportivos, a posibilidade de que o Celta gañase a Copa de España, de que o Deportivo fose campión de liga e de que o Compostela, o Compos ou Esedé, ascendese á máxima división ( 40).

O televisor reflectía o decorado do mundo. Un fluído alleo de sucesos externos. A inauguración do Eurotúnel no Canal da Manga, a dialéctica acerba e monocorde do incipiente José $\mathrm{M}^{\mathrm{a}}$. Aznar, a celebración do Días das Letras dedicado a Luís Seoane, o clamor fétido do terrorismo de ETA, a morte de Bokowski...(46-47).

Outro elemento que contribúe a reforzar a técnica realista é a mención a amigos reais co seu nome propio, como fai no caso de Inés Canosa ou Xulio Valcárcel.

Por último, o contraste entre a escrita e a «realidade» é outro mecanismo empregado. Así sucede cando, na páxina corenta e oito, fai o resumo dun artigo do xornal no que se fala da situación dos hospitais. O que di este artigo vén reforzar o que, pouco antes, se dicía mentres o pai inda estaba ingresado, pero, o que neste caso está escrito fai que esa testemuña previa teña unha maior realidade.

Verbo da técnica, só quedaría engadir que, do mesmo xeito que vimos en Traxectos curtos, o autor emprega os paralelismos e as sentencias que parecen versos (e vén engadirse aos versos dos autores mencionados) para dotar de maior lirismo o texto. Basten como exemplo os seguintes: "Cada bágoa é a infancia que queda en nós retida» (13) ou «Sempre doen menos as bágoas que a ferida máis pequena» $(31)$.

Por último, tamén igual que en Traxectos curtos, os diálogos non veñen marcados por guións senón que se introducen nos parágrafos sen máis marcas textuais.

Concisión, contención e lirismo serían así as características fundamentais deste libro sobre a vida e a morte.

A terceira obra publicada nestes anos é Malas cartas, que aparece en 2010, na colección Mandaio de Biblos. Neste caso, trátase dunha novela que poderíamos clasificar como histórica, escrita «na memoria de José María Torres Cabaleiro, que viviu unha historia moi parecida a esta» (2010: 5) e, dedicada, entre outros, a Elsa Porto Panamá «que me contou unha historia moi parecida a esta».

A novela, de noventa e unha páxinas, está dividida en trinta secuencias cortas, que semellan as dunha película, nas que prima a imaxe. Ten, polo tanto, un estilo fragmentario no que só se reproducen os momentos que o autor considera 
relevantes ou representativos, pero carece de continuidade temporal, e hai, mesmo, momentos de baleiro entre as secuencias que desconcertan o lector, xa que non sabe o que pasou ou qué tipo de relación hai entre os dous momentos que se refiren.

Do mesmo xeito que en Días do final, a novela comeza ao final da historia e, acto seguido, cunha analepsis (ou flashback, dado o estilo cinematográfico) que nos leva tres meses atrás, asistimos ao desenvolvemento lineal da historia. Esta trata do acaecido a Suso, acusado e condenado ao cárcere por un asasinato que non cometeu, debido a «emboscada» (13) preparada por un dos compañeiros de xogo co que tiña contas pendentes, e liberado pola intervención de Ateria. Así mesmo, inclúe as consecuencias disto, que, xunto coa pobreza, fan a Suso emigrar durante sete anos, que se mencionan e constitúen unha prolepses, antes de chegar á fin da obra. O que subxace, porén, como tema principal é a loita de poder sostida nos anos cincuenta (a obra desenvólvese no ano 1951) entre as novas forzas vivas relacionadas coa Falanxe e os antigos poderes das vilas, encarnación dos señores feudais convertidos en caciques, propios da Galiza da época. Neste caso, Suso, representante do pobo, só sería á escusa a partir da cal establecer este pulo de poderes.

Deste xeito, podería dicirse que a novela ten tres grupos de personaxes que desenvolven distintos papeis na obra, que falan de distinto xeito e que se relacionan con distintos lugares.

Por unha banda, atopamos o pobo, que como dicía, está encarnado por Suso, traballador do campo e músico, pero tamén pola súa muller, Lola; os seus fillos, Antonio e Carmen, (inda que apenas aparecen); os seus sogros, Brais e Elvira, e a demais xente da vila ou da aldea: Luis e Sefa (os taberneiros), Paco, Albino etc. que a frecuentan, Desiderio Ribeira (o director da banda de música), Lucía, a costureira, Manuela de Berto ou o carpinteiro Marcelino de Rego, que acadan unha importancia fundamental na evolución da obra. Mesmo a morta, Pepa do Campo, sería parte do pobo e, quizais, o fillo, emigrado en Barcelona, do que se sospeita ao final da novela como posible asasino da nai.

As funcións que desenvolven estes personaxes na obra son fundamentais. Por unha banda, como xa dixen, son o obxecto polo que loitan os poderosos: «Nós somos o gando e eles os tratantes» (77), como di o mesmo Suso unha vez ceibe. Non se trata dunha actitude de protección paternalista, senón de demostrar quen é o máis poderoso. Así queda claro nas palabras dun dos «parroquianos» da taberna que comenta a intervención de Ateria no caso de Suso:

...a ela Suso impórtalle nada. (...) Ela non o fai por facerlle un favor. Ela o que quere é demostrarlle a catro galopíns que andan dándose de señoritos e de donos da vila que antes ten que ela morrer. Ela desfai por lle dar nos fociños aos outros, pero non por caridade, nin por misericordia...(74).

No entanto, os que si o fan por facerlle un favor son os que lle contan a Ateria a historia facendo fincapé nos feitos que poden movela a intervir. É interesante ver que para chegar a ela hai toda unha cadea de personaxes que intervén, de xeito que o autor está a amosar a solidariedade existente entre as persoas do 
pobo que fan por se axudar inda que non sempre se coñezan os uns aos outros de primeira man. Así, Ateria sabe da historia por Marcelino de Rego, que traballa para ela, e el vaille falar por petición de Manuela de Berto, a súa curmán, que coñece de vista a muller de Suso, que decide acudir a ela por recomendación da súa amiga Lucía. Así, mentres o poderosos loitan entre eles, a xente do pobo acada o seu poder por medio dunha rede de apoio mutuo.

Por outra banda, estes personaxes teñen outra función importante na configuración da obra. Como se viu no anterior exemplo, xa sexan os homes na taberna ou as mulleres pola rúa ou á saída da igrexa, van comentando o que pasa e facendo xuízos ao respecto, polo que están a funcionar como unha especia de coro clásico.

Individualmente, algúns dos personaxes son tamén caracterizados e se asocian a determinadas características que lles fan humanos. Así, Luis e Sefa destacan pola súa discreción, o que lles fai merecedores da confianza da xente. Lola, a muller de Suso, representaría a forza e o afán de non render. Pola súa parte, o sogro é, quizais, dos personaxes máis humanos, pois, arrestado xunto co xenro ao principio, delátao para que o ceiben por non poder resistir o frío e a humidade do cárcere. Suso, por outro lado, é o que, de non sabermos que está baseado nunha persoa real, parecería máis idealizado, pois non só perdoa o sogro, senón que, á fin da obra, acode a falar co que o acusou falsamente e accede a traballar con el, inda que non poda perdoalo de todo: «Que Deus llo perdoe. Eu fixen o que puiden» (92) din na frase que pecha a obra.

Como xa dixen, os personaxes do pobo aparecen unidos a lugares concretos. Neste caso, o lugar fundamental é a taberna de Lois (que, ademais, é tenda, como adoita ser en moitas vilas galegas). Tamén, en certo modo, a igrexa, que se relaciona co cura, pero tamén coas mulleres.

O xeito de falar é outra das ferramentas utilizadas para a caracterización. Neste caso, os personaxes empregan unha lingua coloquial, viva e reiterativa, na que con frecuencia atopamos, tamén, vulgarismos e exclamacións. Así, por exemplo, expresións ou diálogos como o que segue aparecen con frecuencia:

- ¡Cago no Deus que os fixo!

- Cabróns, primeiro átanlle as mans e despois pétalle, o fillo de puta ese, semellante hostia. ¡Se rebentase da pura pezoña que ten!

- Bestas, son como bestas, non teñen conciencia.

— ¡Nin conciencia, nin pai! (14-15)

O segundo grupo de personaxes que atopamos son os novos poderosos, persoas que pola súa relación con Régimen acadaron postos de influencia e poder. Neste grupo, atopamos, o primeiro, a D. Domingo, o delator de Suso, do que o mesmo Suso, cando chega a conclusión de que foi el o que lle sinalou como o asasino, pensa o seguinte: 
Tivo que ser así. Claro que foi. (...) Ademais así demostran quen son eles; e que xunto co alcalde, co crego, con catro ricachos que encheron os petos co estraperlo, están eles. E que son quen de facer e desfacer en Vilaio (31).

Don Domingo Trovio Navia, porén, é caracterizado polo narrador en terceira persoa como «facilmente asustable» (34) e bastante mediocre nas súas posicións. Así, «estaba cómodo no Régimen, era adepto, sen dúbida, máis non acérrimo coma outros amigos», «que era ambicioso pero con mesura e que se conformaba cos logros conseguidos», «quería manter os pés na aldea e a alma na vila» (34). Os mesmos compañeiros falangistas insisten neste carácter, como vemos en Don Anselmo: «Tíñao por persoa leal, un pouco morno de máis, pero a lealdade non se lle podía discutir» (39). Este carácter morno e mediano vese tamén no feito de que acusa a Suso porque está enfadado por unha discusión de taberna, porén, despois, preto da morte, arrepíntese e pide perdón. Ademais, como xa se ve nas citas, frecuenta os dos espazos, a taberna e o casino que vai caracterizar a estes novos ricos, polo que resulta un personaxe que se sitúa no medio.

Xunta del, no grupo dos falangistas, atopamos a D. Anselmo López Gómez, avogado grazas as facilidades dadas pola filiación política, camisa vieja, e hábil orador para manter boas relacións coas familias ricas e poderosas. Razóns, todas elas, que fan del o «mando máximo dentro do concello» (39). Don Anselmo aparece na obra como amigo de D. Domingo e como representante dos falangistas que non están situados no medio, pero non ten máis papel nela.

Como representante desta nova oligarquía, D. Anselmo aparece relacionado con lugares como o «Casino de Vilayo», con letreiro de bronce, bar con mostrador de mármore, e teito con medallóns de escaiola (32). O feito de que sexa «Casino de Vilayo» é importante, porque é mostra da diglosia propia da época. Como dixen, a linguaxe vai ser características dos personaxes. Por iso, os $\mathrm{fa}$ langistas, e os que acadaron poder polas ideas políticas van a lugares con nome castelán, pero falan en galego, para deixar claro o estrato social ao que pertencen e a súa condición de novos ricos.

En relación a estes personaxes, é fundamental a presentación do acto conmemorativo da fundación de Falange, celebrado en Vilagarcía o 18 de marzo de 1951 (un día despois do verdadeiro aniversario, para que puidese acudir Raimundo Fernández Cuesta). A funcionalidade narrativa deste acto é, tamén, situarnos no momento histórico e no marco da sociedade tal como era. Así, serve para que saibamos o momento exacto no que están a ocorrer os feitos, e nos da idea do contorno e das reaccións da xente. A meticulosidade coa que Pereira describe o acto e o que o rodea, mesmo coa reprodución de artigos xornalísticos (45) que recollían a nova, mostra, de novo, a meticulosidade documental do autor, reforzada con outras mencións ao fútbol (fala das semifinais da Copa do Generalísimo na páxina 69), ou a anuncios de coches (como a mención á distribución dos Hudson para España, na páxina 71).

Preto destes personaxes, aparecen as forzas vivas da vila, é dicir, o cura, Don Pedro, e o Guarda civil, Don Carlos Montero. Verbo de Carlos Montero, non atopamos moita información máis aló da súa prepotencia e do seu discurso 
franquista oficial. Os outros gardas civís que aparecen, fano como meras pezas do sistema sen capacidade de toma de decisión. Como brazo dos poderosos, son eles os que fan e desfan, como mostra tamén o feito de que, á fin da obra, saibamos que non deixaran entrar á policía secreta para investigar o crime de Pepa do Campo.

Canto ao cura, Don Pedro, preséntase como covarde na defensa de Suso («é boa persoa, pero a misa non vén» p.18), e como conspirador e curioso na súa actividade diaria:

Encantáballe traspasar esa barreira dos territorios privados e persoais. Desenvolvera unha técnica precisa de palabras mornas e calculada familiaridade coa que escaravellar até descubrir os detalles máis delicados, até usurpar segredos e confidencias (25).

Do mesmo xeito que asistimos as celebración dos outros personaxes, na novela aparece a celebración da Semana Santa e, neste caso, as súas prédicas caracterízanse pola ira e a «retórica enfurecida», en «homilías inflamadas e convertidas en reprimendas» a uns fregueses que escoitan «cun ricto de resignación, canseira e medo» (47). É interesante sinalar, en calquera caso, que a actitude deste cura non se xeneraliza na obra para os demais cregos, e, en contraposición ao cura de Trevoedo, as mulleres falan do cura de Vilaio, do que din:

para pola rúa a falar con calquera e non lle importa botarlle unha man aínda que sexa a un pobre. Mesmo oín dicir que volvera polos que mataron cando a guerra. Mira, os curas predicar predican case todos o mesmo, pero logo sonche coma calquera e cada un fai coa súa vida o que lle da a gana (49).

Para rematar, faltaría falar da representante da «nobreza hereditaria» da vila, Ateria (que nin sequera precisa do Dona para inspirar respecto), que recibiu o posición do pai. Ateria, que é descrita como unha muller elegante e discreta, é, así mesmo, unha muller forte, culta e poderosa, con importantes amizades e contactos: «pero non vaias pensar que xente de Franco ou estes becerriños novos de pelo lambido, non, non. Ela é con xente da que tiña poder e cartos xa de antes» (55). Mesmo que os outros personaxes, os seus espazos serven para definila, pero, neste caso, non son espazos públicos senón a súa propia casa, o que redunda na sensación de afastamento con que ela consegue o respecto dos demais e dende a que constrúe as pontes que lle dan o éxito. Así, a súa casa descríbese como «un deses edificios de elegancia discreta, que comezaban a ser considerados antigos por certos novos ricos» (60). Como xa se dixo, a súa función na obra é a de mover os fíos para que Suso quede libre, pero só os move para dar un escarmento os que pensan que poden facer o que queiran na vila sen contaren con ela, persoas ás que non ten respecto ningún:

Pero o que non estaba disposta a consentir era que un principiante, un oficinista ambicioso viñese pisando onde non debía e máis daquel xeito desconsi- 
derado. A iso non estaba disposta, a que a suplantase así como así un calquera, un arribista, un can sen dono, un mediocre ousado (65).

Como non podía ser doutro xeito, Ateria e o cura Don Pedro son os únicos personaxes que fala en castelán na obra.

Canto ao estilo, xa falamos da utilización da linguaxe como xeito de caracterizar os personaxes, pero tamén é interesante termos en conta a linguaxe do narrador, que nos leva, de novo, ao lirismo recorrente de Pereira que, ademais, neste caso, contrasta coa expresión realista e, inda, vulgar dos personaxes. Así, o narrador en terceira persoa, que non é un narrador de todo neutral (como se ve na adxectivación brutal que dedica a algúns personaxes) caracterízase pola utilización dunha prosa lírica, na que con frecuencia atopamos paralelismos e na que, como nos outros libros analizados, fíltranse sentencias que parecen versos e que permiten ao autor afondar nalgúns temas como o paso do tempo, o paradoxo da vida etc. Así, por exemplo, lemos: «Todo é doado para o entendemento dos necios» (18), «Pois iso é vida, estar preparados para o que poida vir. Non sempre son boas as cartas» (35), «Mil imaxes, mil recordos desfacéndose na memoria coma ruínas na néboa» (36), «Por sentir o voo da beleza, contra as aves predadoras das aldraxes» (37) etc.

Nesta obra, en calquera caso, a presenza da voz dos personaxes, xa sexa por medio do diálogo, do monólogo ou do estilo indirecto libre, é tan profusa que, case, a voz do narrador sitúase o mesmo nivela ca deles.

Podemos concluír, por tanto, que esta obra, histórica e baseada en feitos reais, vén reforzar as impresións que xa leváramos verbo do estilo de Pereira con Días do final. Así, podemos dicir que mantén o gusto pola ourivería da linguaxe, polo lirismo e, tamén, polo meticuloso reflexo da realidade do tempo histórico do que está a escribir.

Só o último dos libros publicados, polo de agora, é de poesía. Trátase do libro Tatuaxes, publicado por Libros da Frouma en 2011. O libro contén setenta e sete poemas, nos que ou o fondo ou o tema é Madrid, e seis imaxes da cidade.

Como corresponde á meticulosidade do poeta que xa quedou probada na análise das outras obras, o libro presenta unha estrutura perfecta. Así, despois duns paratextos altamente significativos dos que falaremos a continuación, atopamos o poema «Plano xeral» (15) no que, como cabe esperar polo título, o autor fai un percorrido xeral por toda a súa historia na cidade de Madrid e todo o que significou para el, dende a chegada co seu irmán en xaneiro de 1974, até ese «E segue a combustión sucesiva dos retratos», que deixa aberta a historia madrileña do autor. No poema, xa aparecen os espazos (estación, colexios maiores, «domicilios de clima suave»), os personaxes (o irmán, «noiva, emprego, voda», María) e, como non, o que caracteriza a ollada á cidade de calquera dos madrigalegos: «Ouzande na memoria,/constantemente» (15). A continuación, atopamos unha serie de poemas nos que os espazos míticos da cidade van alternando cos espazos propios e coas persoas que habitan a cidade (Madrid non é só un espazo, é tamén as persoas que a poboan), nunha gradación que deixa os retratos máis importantes (Chus e María) para a fin. Para pechar o libro, o poema «Re- 
parto», que parece facer unha avaliación ou valoración da vida en Madrid, é dicir, da propia vida:

O tempo pasa bruscamente cando

Lembramos. Ao vivilo houbo de todo,

Fugacidade e chumbo, frío e agarimo,

Entusiasmo e declive. Non deixan escoller,

É o que che toque. O destino baralla e decide.

(100)

Volvendo aos paratextos, o primeiro que compre sinalar son as dedicatorias, nas que as persoas queridas relaciónanse coa súa función respecto a Madrid: «A Dino que me presentou Madrid», «A Chus e María, porque reedificaron para min a cidade». A continuación, as citas, de René Char e Vicente Araguas, vén configurar o sentimento dos galegos en Madrid: a casa na memoria, e as impresión sobre a cidade.

Se falamos dos poemas, como xa quedou dito, o tema ou o fondo é a cidade de Madrid. Así, coa mirada atenta e o estilo preciso que o caracteriza, Pereira vai facendo unha collage da cidade. Nela aparecen os espazos que a definen. Por unha banda, lugares míticos como a Gran Vía (43), o Rastro (34), a M-30 (36), o Km 0 (41), Montera (53), Libreros (63), o Retiro (90) Moyano (65), ou Preciados (73); as zonas máis ricas e aparentes, como Serrano, onde «todo é pedigree, degustación, glamour" (74) ou os hoteis de luxo (75); os barrios máis castigadas, como Entrevías (80); os locais consagradas do arte, como o Café Gijón (70), onde nos achegamos «Como se se tratase dun santuario,/con esmero, respecto e devoción», e os lugares de arte alternativas como «tránsito obrigado de apostas e caídas» (71); por último, os espazos cotiáns, como o metro (26) ou os descampados chamados á extinción (29).

Por outra banda, xunta destes lugares, aparecen os propios, os que fan o seu mapa, os seus espazos míticos, como a escola (50) ou o barrio do Pilar (79), lugares de traballo e domicilio; A Clínica Moncloa (95); e tamén os da cultura galega en Madrid: o café Comercial (69) ou a librería galería Sargadelos nas «Décadas esmeraldas», nas que Sargadelos era sinónimo de Inés Canosa: «constante dozura, xenerosidade sen/ cálculo, ollada sen reverso» (93).

Pero na composición que presente Madrid tamén teñen que aparecer os tempos, os momentos, tanto os cotiáns e recorrentes (como as voltas das fins de semana (35), e as das vacacións estivais (55), ou as tardes de domingo (35)) como aqueles que vén de visita cada ano (como a Feira do Libro (91)) ou aqueles que deixaron a cidade e os seus habitantes marcados para sempre, como o $11 \mathrm{M}$ (81) ou a lembranza dos anos da ditadura no poema «Estatua Ecuestre» (83).

No entanto, probablemente, o máis importante da composición da cidade son os rostros das persoas, os encontros, os momentos de amizade. Ás veces, estas persoas aparecen de xeito esquemático, como poboadores dos espazos citados, pero tamén hai nomes propios que habitan o Madrid de Pereira. Así, todos este nomes van desfilando polos poemas, ben no texto, como no caso de Inés Cano- 
sa, ben nas dedicatorias, como ocorre con Maite Dono, Luz Pichel, Begoña Regueiro, Lucía Ferrer, Pilar Fuentes, Roberto Pascual ou Ana/Natalia; e, certamente, como xa se dixo, nos poemas dedicados a Chus, a María, e, aínda, a el mesmo, nas preguntas que lle fai a cidade no penúltimo poema (99), e a resposta contundente: «Pero a diferenza entre o que fun e o que son/ non se mide con nostalxia» (99).

Cómpre dicir que, xunto destes poemas, hai algúns nos que non aparece a referencia explícita a Madrid, aínda que poden englobarse en situacións ou experiencias vividas nesta cidade. Así, atopamos varios poemas que tocan temas moi queridos polo autor. Lemos, por exemplo, poemas de amor, como «Amada» (23) ou «Ámote» (44). Tamén de pesimismo, que, ás veces, aparece mitigado pola esperanza ou combatido dalgún xeito con apertas (72) ou o agarimo:

\author{
ABEIRO \\ Construír \\ un planeta de agarimo, \\ para transitar o agre ermo, \\ para soportar o noxo, \\ para amortecer a barbarie, \\ para minguar o cativerio. \\ Para non estar sós (87).
}

Por último, sen ser un poeta eminentemente social, Manuel Pereira nunca esquece a voz da denuncia e, neste caso, aparece a protesta contra a especulación inmobiliaria («Eventual», 29), os intereses e avaricias que ameazan as árbores da cidade («Resistencia», 33), as condicións miserentas nas que viven algunhas persoas («Reclusión», 60), o terrorismo («Tiranía» na páxina 82 e «11M», na páxina 81) e os malos tratos («Furtivo», p.84).

No que se refire ao estilo, o autor segue a liña que emprendera en poemarios anteriores, especialmente despois de Inventario de fragmentos. Deste xeito, o estilo do autor caracterízase pola concisión e a precisión; pola busca da palabra exacta en poemas curtos nos que non aparece nin un verso máis dos estritamente necesarios. Trátase, ademais e en consecuencia, dun estilo netamente nominal no que se busca crear a imaxe e provocar a suxestión máis que narrar feitos. Así, fronte as enumeracións recorrentes, os adxectivos diminúen e os verbos case desaparecen nun acercamento, cada vez maior, ao esencial, a poesía pura, a imaxe fixa, como dunha fotografía ou un filme, pero no que non haxa argumento, como o labor dun «coleccionista de fotogramas» (48) como el mesmo di.

Deste xeito, as figuras que máis aparecen son as relacionadas co paralelismo, no campo da dicción, e as que ten que ver coa creación de imaxes, no campo do pensamento. Respecto a isto, é interesante sinalar o xogo que se establece en ocasións entre o poema e o título. Así, ás veces, os títulos funcionan como unha metáfora que se explica no poema («Ballet», «Retablo» (25), «Cadro abstracto» (16)...), ou como unha palabra que se deduciría do contido do poema, 
que lle da un senso especial, ou que, mesmo, explica a metáfora do poema, pero que non aparece nel («Semáforo» (46), «Remorsos» (20), «Resistencia»).

A modo de mostra, podemos ver os seguintes poemas:

\section{BALLET}

Ao lonxe

a urbe densa

so a danza nocturna de

bolboretas de neon.

(19)

\section{RESISTENCIA}

Plátanos, magnolios, acacias, cedros...

Árbores en pugna. Ameazados por

Velenos e avaricias. Milagrosamente

vivos no seu confinamento. Seguen

sen rancor coa súa doazón constante,

abeiro, osíxeno, lecer.

(33)

Só nun caso, atopamos un soneto, non por coincidencia, no poema que fala do Café Gijón, é dicir, o que entronca coa tradición.

En calquera caso, en xeral, podemos afirmar que o libro segue as tendencias estilísticas dos libros de poemas previos, co que consegue afianzar a voz poética de Pereira, mentres avanza na busca da palabra esencial, da precisión na expresión, como dicía ao principio, e da minuciosidade na mirada.

No que toca a temática, os temas principais do autor seguen presentes (como o amor ou a soidade), pero a presenza de Madrid faise moito máis importante, o que, dende o meu punto de vista, incide, inda máis, na súa clasificación como poeta madrygalego: a memoria sempre na casa, a mirada sempre impregnada de Galicia, pero, ás veces, o obxecto mirado pertence a Madrid.

\section{CONCLUSIÓNS}

Con todo o visto até aquí, parece que xorden dúas preguntas as que convén contestar. A primeira tería que ver coa afirmación que fixen o principio acerca da calidade poética de todo o que fai Pereira e das características comúns que podemos atopar mesmo na prosa que no verso. A segunda sería verbo da posición da nova obra respecto da anterior.

Respecto á estilística común no verso e na prosa, bastante se dixo xa, así que só queda recoller as características que aparecen en ambos xéneros e que deixan claro a mesma identidade do autor. 
En primeiro lugar, podemos dicir que todas as obras estudadas se caracterízan pola concisión, é dicir, son obras curtas. Os poemas e os contos adoitan ser curtos pola natureza do xénero, pero, neste caso, tamén as novelas son curtas, pois ningunha delas pasa das cen follas e, ambas as dúas, vén divididas en secuencias que fan que as unidades inda sexan máis breves e, polo tanto, máis intensas.

Por outro lado, sobra repetir que o lirismo está presento tanto nos poemas como nas obras en prosa, nas que, como vimos, mesmo aparecen frases que semellan versos.

A precisión lingüística e o traballo de ourivería coas palabras, que sinalamos en todas as obras, sería outro trazo común, así como a meticulosidade do observador que, nas novelas leva o autor a recoller até o derradeiro detalle da época sobre a que escribe, e, nos poemas, lévao a deixar constancia inda das cousas máis miúdas.

Tamén a paixón polo cine, que o fai crear secuencias ou poemas absolutamente visuais é algo que se reflicte en todos os libros.

Os temas, que non deixan de ser reflexións sobre a vida e a morte, sobre os xeito de afrontar a vida, sobre o paso do tempo ou os conflitos, xa sexan por poder ou por diferenzas xeracionais, aparecen en todos os libros, igual que aparecían nas obras anteriores. Con todo, como fixera previamente, cada libro se centra especialmente nun destes temas: a morte, os traxectos da vida e os encontros, as loitas de poder na Galiza dos anos cincuenta, ou a vida en torno a unha cidade, Madrid.

Respecto á segunda pregunta, a resposta tamén se pode entrever no que xa se dixo. Os temas son semellantes, o estilo, nunha progresión constante, segue a se recoñecer, polo que podemos dicir que, nas últimas obras, a voz de Pereira se afianza nunha gama máis ampla de xéneros.

Por outra banda, os paralelismos entre algunhas das obras son evidentes. Así, se entre as primeiras obras tiñamos Todo morte, posiblemente máis centrado na nai, agora atopamos Días do final, no que o pai é o protagonista. En ambos libros achamos un ton comedido e varias reflexións xerais sobre a morte. No poemario, na primeira das cinco partes, o que lemos son estas reflexións nas que aparece o concepto da morte cun suxeito plural que abarca a todos os seres humanos, segundo a idea de Heidegger de que o home e un ser para a morte. Na novela, como se dixo, moitas das conversas de hospital cos fillos dos outros pacientes versan sobre este tema, e tamén destaca a idea de que a vida é a excepción e de que, coa morte dos pais, pasamos a estarmos na primeira fila.

Igualmente, nas dúas obras, a lembranza dos seres queridos que morreron está presente, como xa se explicou.

Así, podemos confirmar algo que o mesmo Pereira afirma: a importante pegada que deixou a morte na súa vida.

Por outra banda, podemos atopar semellanzas entre $O$ libro das viaxes e Traxectos curtos, xa que, unha en verso e a outra en prosa, ambas tratan de facer a 
análise da viaxe na súa dimensión concreta e na súa dimensión vital. Nas dúas, a viaxe tamén equivale á vida, nas dúas queda espazo para as persoas que pasaron pola nosa vida e desapareceron, e, nas dúas, hai momentos en que o autor se centra na viaxe en si.

Parece, pois, que as teimas do autor aparecen dun xeito ou doutro, sempre as mesmas e sempre diferentes, na evolución constante dunha pluma que inda ten moito que ofrecernos.

\section{BIBLIOGRAFÍA}

Acuña, A. (2009) Facer literatura galega en Madrid (1950-2000), Santiago de Compostela, Universidade Santiago de Compostela.

Losada Castro, Basilio (1990) Poesía gallega de hoy, Visor, Madrid.

Mejía Ruiz, C. + Tudoras, L. E. (2003) «Poetas gallegos contemporáneos-poetas rumanos: tendencias, coincidencias, traducciones», Revista de Filología Románica, nº 20, 209-232.

Nogueira, M. X. (2003) «A poesía galega actual. Algunhas notas, necesariamente provisorias, para un estado da cuestión», Madrygal, Revista de estudios gallegos, n. ${ }^{\circ} 6$, pp. 85-97.

Pereira, M. (2005) Traxectos curtos, A Coruña, tresCtres.

Pereira, M. (2007) Días do final, Vigo, Galaxia.

Pereira, M. (2010) Malas cartas, A Coruña, Biblos.

Pereira, M. (2011) Tatuaxes, Santiago de Compostela, Libros da Frouma.

Regueiro Salgado, B. (2006) «Manuel Pereira Valcárcel: poesía de la experiencia en la Galicia actual», en Madrygal, 9, 103-113.

Rodríguez, L. (1986) Desde a palabra, doce voces. Nova poesía galega, Barcelona, Sotelo Blanco.

Rodríguez González, O. (2006) «Canon y literaturas miorizadas: las letras catalanas y gallegas en el sistema hispánico y su proyección en el canon europeo (I)» en Mil Seincientos dieciséis, Anuario 2006, vol. XI, 169-178. 
